\title{
Emerging hazard for women of new era: ovarian malignancy.
}

1. M.Phil (Histopathology) Assistant Professor Pathology UMDC Faisalabad.

2. M.Phil (Histopathology) Assistant Professor Pathology UMDC Faisalabad.

3. M.Phil (Histopathology) Assistant Professor Pathology UMDC Faisalabad.

4. M.Phil (Histopathology) Assistant Professor Pathology UMDC Faisalabad.

5. FCPS (General Surgery) Assistant Professor Surgery UMDC Faisalabad.

6. M.Phil (Histopathology) Professor and HOD Pathology UMDC Faisalabad.

Correspondence Address: Dr. Khadija Saleem Department of Histopathology UMDC Faisalabad. drkhalidsleem82@gmail.com

Article received on: 25/02/2021

Accepted for publication: $12 / 06 / 2021$
Khadija Saleem', Tabinda Roheen ${ }^{2}$, Faiza Wattoo ${ }^{3}$, Sadia ljaz ${ }^{4}$, Farhan Javed ${ }^{5}$, Shazia Aslam ${ }^{6}$

ABSTRACT... Objective: The present study aims to assess the incidence of ovarian malignancies and its rise from 2010 to 2020 at subnational levels in tertiary care hospital in Faisalabad. Study Design: Retrospective Analysis. Setting: Madina Teaching Hospital, Faisalabad. Period: January 2010 and January 2020. Material \& Methods: After the precise processing of data extracted from the Pakistan Cancer Registry and hospital records, annual standardized incidence and increasing trends were calculated during the period of the study. Results: A total of 103 patients of ovarian tumors were included in the study. During this period 550 oophorectomies were received out of 4752 (11.5\%) gynecological admissions. 103 cases(18.73\%) selected after formulating an inclusion criteria. The data showed 75 benign (74.25\%) cases, 7 borderline tumors (6.93\%) and 21 malignant tumors $(20.79 \%)$. Age of patients ranged from 14-69 years. Out of all the benign tumors, serous cystadenomas were most common (45.33\%) followed by mucinous cystadenomas (24\%), dermoid cyst $(30.66 \%)$. Commonest malignant tumor was serous cystadenocarcinoma (42.85\%) followed by mucinous cystadenocarcinoma (33.33\%) granulosa cell tumors (14.28\%) krukenberg tumor (4.76\%) and dysgerminoma (4.76\%). Clinical signs and symptoms were mostly abdominal pain and distention. Conclusion: Ovarian malignancies are increasing in frequency at an early age with relatively longer duration of symptoms. This emphasizes the need of early detection and management because of desirability of maintaining patient's menstrual and reproductive capabilities.

Key words: $\quad$ Benign, Malignant, Morbidity, Mortality, Ovarian.

Article Citation: Saleem K, Roheen T, Wattoo F, ljaz S, Javed F, Aslam S. Emerging hazard for women of new era: ovarian malignancy. Professional Med $\mathrm{J} \mathrm{2021;}$ 28(9):1229-1233. https://doi.org/10.29309/TPMJ/2021.28.09.6446

\section{INTRODUCTION}

Ovaries are the paired pelvic organs lying on the lateral aspect of uterus close to the pelvic wall measuring approximately $4 \times 2 \times 1 \mathrm{~cm}$ and weighing 5 to 9 gms. ${ }^{1}$ Ovarian neoplasms display a wide disparity in structure and biological behavior. There are numerous types of ovarian tumors, and overall they fall into benign, borderline and malignant catagories. ${ }^{2}$ Ovarian carcinoma represents the sixth most common female cancer and fourth leading cause of death due to cancer in women. ${ }^{3}$

Ovarian tumors are notorious as they spurt attention in early stage due to relatively larger space available in pelvis and abdominal cavity for growth. They only come to attention when they have attained enormous size. ${ }^{4}$ Commonly surgery is mandatory for treatment of pelvic and adnexal masses. Prognosis of effected patients depends upon Histopathological as well as immunological diagnosis. ${ }^{5}$

There is no racial predisposition to ovarian sex cord stromal tumors or ovarian germ cell tumors. Ovarian tumors are generally challenging to identify until they are advanced in stage or size, as the symptoms are ambiguous and manifest over time. ${ }^{6}$ Some ovarian tumors, notably the sex cord stromal tumors require surgical intervention only. Meanwhile others require post resection chemotherapy; this applies to all germ cell tumors and vast majority of ovarian epithelial neoplasms. ${ }^{7}$

The proposed study in an attempt to identify the rise in the incidence of ovarian malignancies annually experienced in a tertiary care setting in Faisalabad. 


\section{MATERIAL \& METHODS}

This is a retrospective analysis of the patients presenting between January 2010 and January 2020. After approval from hospital administration andethical reviewcommittee, (TUF/Dean/2021/09) data was retrospectively collected from patient records. Histopathology reports submitted to pathology department Madina teaching hospital were reviewed.

Formalin fixed oophorectomies, hysterectomies with oophorectomies, pelvic masses, adnexal masses that were received from department of Gynecology and Obstetrics and General Surgery of Madina Teaching Hospital after surgical procedure were processed in histopathology are included in the study.

Inflammatory disorders, cysts (epithelial inclusion, follicular, corpus luteal, para ovarian, para tubal, polycystic ovaries, endometriosis), lesions of pregnancy (solitary luteinized follicular cysts, hyperreactio luteinalis, pregnancy luteoma, ovarian ectopic) oophorectomies having inconclusive results and autolyzed specimens were excluded.

\begin{tabular}{|c|c|c|c|}
\hline Year & Benign Tumors & Borderline & Malignant Tumors \\
\hline 2010 & $3(4.0 \%)$ & $0(0 \%)$ & $0(0 \%)$ \\
\hline 2011 & 4 (5.33\%) & $0(0 \%)$ & $1(4.76 \%)$ \\
\hline 2012 & $6(8.0 \%)$ & $0(0 \%)$ & 2 (9.52\%) \\
\hline 2013 & 7 (9.33\%) & $1(14.28 \%)$ & $1(4.76 \%)$ \\
\hline 2014 & 7 (9.33\%) & $0(0 \%)$ & 2 (9.52\%) \\
\hline 2015 & 8 (10.66\%) & 1 (14.28\%) & $1(4.76 \%)$ \\
\hline 2016 & 8 (10.66\%) & 2 (28.57\%) & 2 (9.52\%) \\
\hline 2017 & 6 (8.0\%) & $0(0 \%)$ & $1(4.76 \%)$ \\
\hline 2018 & 12 (16.00\%) & $0(0 \%)$ & 3 (14.28\%) \\
\hline 2019 & 13 (17.33\%) & 3 (42.86\%) & 7 (33.33\%) \\
\hline 2020(Jan) & 1 (1.33\%) & $0(0 \%)$ & $1(4.76 \%)$ \\
\hline
\end{tabular}

Table-I. Annual incidence of ovarian tumors $(n=103)$.

\begin{tabular}{|c|c|c|c|c|c|c|c|c|}
\hline \multirow{2}{*}{$\begin{array}{l}\text { Age groups (years) } \\
\leq 20\end{array}$} & \multicolumn{2}{|c|}{ Benign $(n=75)$} & \multicolumn{2}{|c|}{ Border line $(n=7)$} & \multicolumn{2}{|c|}{ Malignant $(n=21)$} & \multicolumn{2}{|c|}{ Total $(n=103)$} \\
\hline & 13 & $17.3 \%$ & 0 & 0 & 1 & $4.76 \%$ & 14 & $13.59 \%$ \\
\hline $21-30$ & 25 & $33.33 \%$ & 0 & 0 & 3 & $14.28 \%$ & 28 & $27.18 \%$ \\
\hline $31-40$ & 16 & $21.33 \%$ & 3 & $42.85 \%$ & 3 & $14.28 \%$ & 22 & $21.35 \%$ \\
\hline $41-50$ & 12 & $16.00 \%$ & 2 & $28.57 \%$ & 7 & $33.33 \%$ & 21 & $20.38 \%$ \\
\hline $51-60$ & 04 & $5.33 \%$ & 2 & $28.57 \%$ & 5 & $23.80 \% \%$ & 11 & $10.67 \%$ \\
\hline$>60$ & 5 & $6.66 \%$ & 0 & 0 & 2 & $9.52 \%$ & 7 & $6.79 \%$ \\
\hline \multicolumn{9}{|l|}{ Parity } \\
\hline Nullipara & 27 & $36.0 \%$ & 0 & 0 & 1 & $4.76 \%$ & 28 & $27.18 \%$ \\
\hline Primipara & 12 & $16.0 \%$ & 3 & $42.85 \%$ & 7 & $33.33 \%$ & 22 & $21.35 \%$ \\
\hline Multipara & 36 & $48.0 \%$ & 4 & $57.14 \%$ & 13 & $61.90 \%$ & 53 & $51.45 \%$ \\
\hline
\end{tabular}

\section{RESULTS}

A total of 103 cases were included in the study. During this decade, total 4752 ovarian samples were received from gynecological and surgical theatres. Hence the incidence of ovarian tumors turns out to be $2.74 \%$. Out of these 75 were benign, 7 borderline and 21 were malignant tumors. The annual incidence of ovarian tumors is shown in Table-I.

The patient's statistics according to age group and parity are highlighted in Table-II. Mostly the benign tumors were seen in 21-30 (33.33\%) years age group followed by $31-40$ (21.33\%), borderline or atypical proliferative or tumors of low malignant potential occurred in $31-40$ age groups (42.85\%) and malignant tumors presented in 41-50 years (33.33\%) followed by $51-60$ years $(23.80 \%)$. The incidence of benign tumors in the age group 2130 years was $33.33 \%$ followed by $31-40$ years in which the incidence of benign was $21.33 \%$. All the three categories of tumors were common in multipara: $48 \%$ of benign, $57.14 \%$ of borderline and $61.90 \%$ malignant respectively. 
Out of the total of 103 patients who were included in the study, 45 (43.68\%) patients presented with abdominal pain, 29 (28.15\%) had abdominal mass, 13 (12.62\%) patient encountered ovarian neoplasm during infertility work up however, for $16(15.53 \%)$ of the study population, ovarian tumor was an incidental finding.

\section{Clinical Presentation}

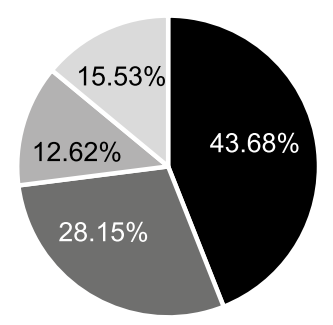

pain $\square$ abdominal mass $\square$ infertility $\square$ incidental

The tumor type after surgical resection was confirmed by histopathological diagnosis. Surface epithelial tumors 75/103 (72.81\%) dominated all other tumor types regardless of benign, borderline or malignant category followed by germ cell tumors $24 / 103$ (23.30\%), and granulosa cell tumors $3 / 103(2.91 \%)$ and 1 case of krukenberg tumor $(0.97 \%)$.

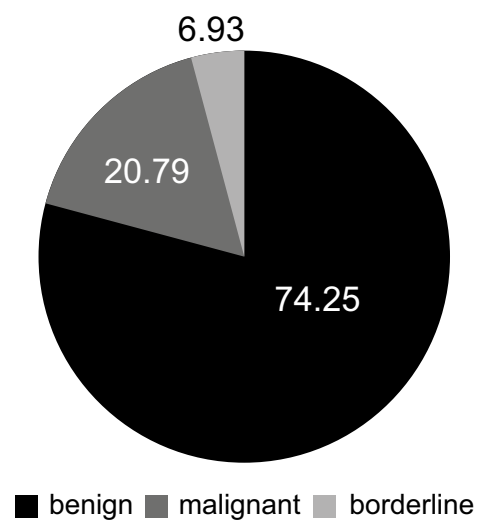

Encompassing the total number of cases (103) considered in the study, 75(74.25\%) were benign, 7 (6.93\%) were borderline and $21(20.79 \%)$ were malignant. The most common benign tumor was serous cystadenomas $45.33 \%$, followed by mucinous cystadenomas $24.00 \%$ and dermoid cyst or mature teratomas were $30.66 \%$. Borderline tumors or atypical proliferative were accounted to be $6.93 \%$. Commonest malignant were serous cystadenocarcinoma $42.85 \%$ followed by mucinous cystadenocarcinoma which were $33.33 \%$. The granulosa cell tumors were $14.28 \%$. Krukenberg tumor and dysgerminoma were $4.76 \%$ each.

\section{DISCUSSION}

Ovarian cancer is the leading cause of morbidity and mortality among women of reproductive age. Its incidence varies by age, socioeconomic status, region, ethnicity and histological subtype. ${ }^{8}$ It is an intriguing tumor that bears exceptional clinical behavior, malicious metastatic potential and varied histogenesis. From being a silent dweller of the wide pelvic space to enormous masses, ovarian neoplasm can impersonate itself and present as an accidental finding in the routine health work-up. In countries like Pakistan, tumors of the female genital tract are overlooked and long elapsed unless presented with huge corporal debility. In a study calculating the international incidence of ovarian cancers among five continents in the year 2017, Asia showed a gradual rise in incidence in a period of ten years. ${ }^{9}$

The ovarian tumors are categorized as benign, borderline and malignant depending upon the predominant cell type, configuration of growth, cellular atypia and intrusiveness. In our study, out of the total 103 subjects considered, the proportion of benign cases was 75 (74.25\%), 7 borderline tumors (6.93\%) and 21 malignant tumors (20.79\%).In a study in India, Sharma P et al reported $40.2 \%$ benign, $4.1 \%$ borderline and 55.8\%malignant cases out of the total 122 subjects. ${ }^{10}$ In another study, $73.52 \%$ benign and $26.47 \%$ malignant cases were reported showing increased trend of benign histogenesis in females of reproductive age..$^{11}$ Similarly, in another study, comparison of different categories of ovarian neoplasms revealed $30 \%$ increased probability of malignant tumors in post-menopausal women. ${ }^{12}$

In our study, the likelihood of having benign ovarian tumors is inversely related to parity. Primipara have 3 times (16\%) less potential to develop benign ovarian tumors as compared to multipara that had $48 \%$. Likewise, the chances 
of development of malignant tumors is more in multipara $(61.90 \%)$ as compared to Nullipara (4.76\%) and Primipara (33.33\%). Similarly, in a study Vicchia $\mathrm{C}$ et all showed relationships of parity and ovarian malignancies in an inverse manner. ${ }^{13}$ In another study, the percentage of development of ovarian tumors was more in multipara (89.3\%) as compared to Nullipara (10.7\%) in a total of 122 women considered. ${ }^{10}$ The age of the patients considered in our study were from 12 years to 68 years median age being 32 years. All the tumor categories benign, borderline and malignant were found in all age groups. Overall, child bearing age group (20s to early30s) had maximum proportion of benign and borderline tumors, with 21-30years having 33,33\% chances , followed by $31-40$ years with $21.33 \%$ likelihoods as compared to $5.33 \%$ in postmenopausal age groups. Similarly, the proportion of borderline tumors was $42.85 \%$ more in $31-40$ years as compared to $28.57 \%$ in succeeding years. The age groups of $41-50$ and $51-60$ years had $33.33 \%$ and $23.80 \%$ chances, respectively of developing malignancy as compared to $14.28 \%$ in women of child bearing age (Table-II). Our findings are in accordance with a study conducted by Iftikhar F.et al in which out of 107 oophorectomies, $86.99 \%$ were benign and $13.01 \%$ malignant and mostly the benign cases were seen in $<40$ years of age as compared to malignant cases in $>40$ years of age. ${ }^{14}$ Similarly, in another study, benign tumors were more prevalent in 21-30 years which was $28.2 \%$ followed by $22.3 \%$ in $31-40$ years $^{12}$. In our study, the commonest benign tumor was serous cystadenoma(45.33\%) followed by mucinous cystadenoma(24.00\%). Likewise, the commonest malignancy was serous cystadenocarcinoma (42.85\%) followed by mucinous cystadenocarcinomas (33.33\%) inferring the fact that serous tumors are more common compared to mucinous tumors and other types. This finding is inconsistent with the studies of Khan MA.et al that also shows among 95 subjects that serous tumors were $49.5 \%$ followed by mucinous $16.8 \%$ and teratomas $(15.8 \%) .^{15}$ Correspondingly another study showed serous cystadenocarcinoma was the commonest malignancy (33.33\%) among 855 adnexal masses enrolled in the study. ${ }^{16}$ In the same way, Ahmed M. et al in a study of 186 individuals undergoing surgeries for adnexal masses proved serous cystadenoma to be the commonest benign tumor (37.98\%) out of $84.95 \%$ total and serous cystadenocarcinoma to be the commonest malignancy $36.00 \%$. $^{17}$

The clinical presentation of ovarian tumors remains inconstant. Majority of the females approaching the outpatient clinics in our set up presented with pain $(44.00 \%)$ in pelvic or the lower abdominal region and majority females who were later diagnosed to have malignant lesions were post-menopausal harboring adnexal masses $(29.00 \%)$ in their pelvic cavities. A major concern for a few females enrolled in the study was infertility (14.00\%) and in a few percentage, adnexal tumors were incidentally found $13.00 \%$ during their routine health work up for other issues. In another study, out of the total of 110 patients, $76.00 \%$ presented with pain in abdomen. ${ }^{18}$ Similarly, Upreti P. et al in a study revealed total of 172 cases, in which $48.84 \%$ patients presented with pain in abdomen preceded by $20.93 \%$ of the patients in which ovarian tumor presented as incidental finding. ${ }^{12}$

\section{CONCLUSION}

Ovarian malignancy is a major health concern in females of reproductive age in Pakistan. Its frequency is increasing at an early age. Prompt detection as well as screening of population is mandatory for prevention of loss of one's reproductive capabilities.

Copyright $(12$ June, 2021.

\section{REFERENCES}

1. Craig ME, Sudanagunta S, Billow M. Anatomy, Abdomen and Pelvis, Broad Ligaments. [Updated 2020 Apr 17]. In: StatPearls [Internet]. Treasure Island (FL): StatPearls Publishing; 2020 Jan.

2. Sebajuri JM, Magriples U, Small M, Ntasumbumuyange D, Rulisa S, Bazzett $\square$ Matabele L. Obstetrics and gynecology residents can accurately classify benign ovarian tumors using the international ovarian tumor analysis rules. Journal of Ultrasound in Medicine. 2020 Jul; 39(7):1389-93. 
3. Weiderpass E, Hashim D, Labrèche F. Malignant tumors of the female reproductive system. In Occupational Cancers 2020 (pp. 439-453). Springer, Cham.

4. He G, Zhao J, Yang Z, Zhao Z, Bai Y, Xiong W. Comparison of image features and diagnostic value of color Doppler ultrasound and two-dimensional ultrasound in the diagnosis of ovarian sex cordstromal tumors. Oncology Letters. 2020 Aug 1; 20(2):1671-6.

5. Lee WL, Wang PH. Immunology and ovarian cancers. Journal of the Chinese Medical Association. 2020 May $1 ; 83(5): 425-32$.

6. Falborg AZ, Vedsted P, Menon U, Weller D, Neal RD, Reguilon I, Harrison S, Jensen H, ICBP Module 4 Working Group. Agreement between questionnaires and registry data on routes to diagnosis and milestone dates of the cancer diagnostic pathway. Cancer Epidemiology. 2020 Apr 1; 65:101690.

7. Piperos T, Theodoulou K, Zarokosta M, Papapanagiotou I, Foutsitzi A, Varaltzidou A, Sgantzos M, Tsiaousis I, Mariolis-Sapsakos T. Extended Resections for Ovarian Cancer-Results and Complications. European Journal of Surgical Oncology. 2020 Feb 1; 46(2):e112.

8. Di Donato V, Di Pinto A, Giannini A, Caruso G, D’Oria O, Tomao F, Fischetti M, Perniola G, Palaia I, Muzii $L$, Panici $P B$. Modified fragility index and surgical complexity score are able to predict postoperative morbidity and mortality after cytoreductive surgery for advanced ovarian cancer. Gynecologic Oncology. 2021 Apr 1; 161(1):4-10.

9. Coburn SB, Bray F, Sherman ME, Trabert B. International patterns and trends in ovarian cancer incidence, overall and by histologic subtype. Int J Cancer. 2017 Jun $1 ; 140(11): 2451-2460$.
10. Sharma P, Rao PS, Mogra N, Talreja K. Histopathological study of ovarian tumours in a tertiary healthcare centre of southern Rajasthan. Indian Journal of Pathology and Oncology. 2020 Nov 15; 7(4):561-6.

11. Kumari A, Singh N. Clinical profile of patients presenting with ovarian tumors at a tertiary care teaching Hospital in Jharkhand, India.

12. Upreti P, Reddy GT. A retrospective observational study of clinicopathological spectrum of ovarian tumors. Indian Journal of OBGYN. 2021; 7(2):157-62.

13. La Vecchia C. Ovarian cancer: Epidemiology and risk factors. European journal of cancer prevention. 2017 Jan $1 ; 26(1): 55-62$.

14. Iftikhar F, Anum H, Iftikhar N, ljaz A, Gul N. Histological pattern of ovarian neoplasms and their age wise distribution-study conducted At A Tertiary Care Hospital. Journal of Rawalpindi Medical College. 2018; 22(S-2):73-6.

15. Khan MA, Afzal S, Saeed $H$, Usman $H$, Ali $R$, Khan MZ, Mumtaz A, Ramazan N, Fatima A, Haider J, Latif A. Frequency of ovarian tumors according to WHO histological classification and their association to age at diagnosis. Annals of King Edward Medical University. 2017 Jun 10; 23(2).

16. Ahmad Z, Kayani N, Hasan SH, Muzaffar S, Gill MS. Histological pattern of ovarian neoplasma. Journal of Pakistan Medical Association. 2000; 50(12):416.

17. Ahmed M, Afroze N, Sabiha M. Morphological Pattern of Ovarian Tumour: Experience in a Tertiary Level Hospital. Journal of Bangladesh College of Physicians and Surgeons. 2018 Jan 29; 36(1):5-10.

18. Wasim T, Majrroh A, Siddiq S. Comparison of clinical presentation of benign and malignant ovarian tumours. JPMA. The Journal of the Pakistan Medical Association. 2009 Jan 1; 59(1):18.

\begin{tabular}{|c|l|l|l|}
\hline \multicolumn{2}{|c|}{ AUTHORSHIP AND CONTRIBUTION DECLARATION } \\
\hline Sr. \# & \multicolumn{1}{|c|}{ Author(s) Full Name } & \multicolumn{1}{|c|}{ Contribution to the paper } & Author(s) Signature \\
\hline 1 & Khadija Saleem & $\begin{array}{l}\text { Data collection \& } \\
\text { Complitation. } \\
\text { Statsitical analysis. }\end{array}$ \\
\hline 2 & Tabinda Roheen & Manuscript writing. \\
\hline 3 & Faiza Wattoo & $\begin{array}{l}\text { Manuscript writing, Proof } \\
\text { reading. } \\
\text { Proof reading. }\end{array}$ \\
\hline 5 & Farhan Javed & $\begin{array}{l}\text { Scknowledgement, Proof } \\
\text { reading. }\end{array}$ \\
\hline
\end{tabular}

